\section{Reliance on the citation index undermines the study of biodiversity}

Sir- The popularity of the Science Citation Index (SCI) as a measure of 'good' science is damaging basic taxonomic work, without which the study of biodiversity would not be possible.

Basic taxonomic work is not highly cited, except in 'hot' taxa like the genus Homo. The number of authors citing a paper during the short period of time (ten years) that the SCI uses for its statistics is relatively low. But taxonomy papers continue to be referred to and cited for more than a century after their publication. Almost every good taxonomic paper becomes a classic in the literature.

High-quality basic taxonomic work the description of new taxa and revision of older ones - is expensive and timeconsuming. Many of the most interesting finds are from 'exotic' locations, requiring travelling, sampling, preparing, sending back collections, writing descriptions, illustrating and so on. The resulting papers are rated low in the SCI, even when published in high-quality specialist journals, and are unlikely to impress managers or funding agencies.

So a paradox arises: concern for biodiversity goes together with a dismissal of the foundation of any biodiversity work, which is the proper description of taxa. If there is reluctance to fund this kind of work because of low citations, and with fewer journals available to publish their findings, the most basic research in biodiversity is doomed to disappear, as is already happening.

Antonio G. Valdecasas*,

Santiago Castroviejo $\dagger$, Leslie F. Marcus $\ddagger$

${ }^{\star}$ Museo Nacional de Ciencias Naturales (CSIC), José Gutierrez Abascal 2, 28006 Madrid, Spain

$\dagger$ Real Jardín Botánico (CSIC), Plaza de Murillo 2, 28014 Madrid, Spain

$\ddagger$ Department of Biology, Queens College of City University of New York, Flushing,

New York 11367, USA

\section{Proteomics could be key in battle against malaria}

Sir-A human proteome project may be premature (Nature 402, 703; 1999), but cataloguing proteins of life-threatening single-celled organisms such as the human malaria parasite Plasmodium falciparum, and another intracellular parasite,

Leishmania, will be interesting, as genome sequencing of these parasites is close to completion.
Understanding the activity of all proteins will be "frustratingly tantalizing" for now, but investigators cannot wait for the advanced technologies they envisage. The creative imagination and ingenuity of the human mind will take up the challenge by employing tomorrow's technologies today, on a limited scale. With these parasites, even two-dimensional protein profiles will be useful in exploring some important issues - investigating the elusive chloroquine-resistance mechanism, for instance, by comparing two-dimensional gels of chloroquinesensitive and -resistant clones of P. falciparum.

Employing tricks such as zoom gels, it may be possible to identify the protein or proteins involved in imparting drug resistance to these parasites. Identification of the drug-resistant/sensitive protein markers will provide a lead in developing new antimalarial drugs or reviving chloroquine efficacy.

The proteomics conducted on these organisms should be carried out on a large scale. It has much to offer and requires the immediate attention of the developed world - after all, it is a matter of tropical health in a global village.

Virendra K. Bhasin

Department of Zoology, University of Delhi, Delhi 110007, India

\section{$X$ chromosomes forget where they came from}

Sir - In an excellent News and Views Feature on the future of somatic nucleartransfer cloning, J. B. Gurdon and Alan Colman (Nature 402, 743; 1999) express concern about the inactive $\mathrm{X}$ chromosome when female cells are used in cloning. If the inactive $\mathrm{X}$ chromosome does not become reactivated by exposure to egg cytoplasm, they wonder whether embryos reconstructed from a donor containing an inactive maternal $\mathrm{X}$ chromosome be viable.

On this point they need have few worries. In early embryos of eutherian mammals, the X chromosome derived from the father is indeed distinguished from that coming from the mother, and is preferentially inactivated in the first two tissues to differentiate (trophoblast and primary endoderm, both of which contribute exclusively to the placenta and extra-embryonic membranes). Thereafter, however, the X chromosomes 'forget' which parent they have come from: they are inactivated at random in the cells contributing to the fetus and retain no trace of their parental origin.

Incidentally, it is legal in the United Kingdom to use human eggs to create an embryo, if the aim is to satisfy one of the purposes specified in the 1990 Human Fertilization and Embryology Act (which does not include research on cell or tissue therapy). An amendment seeking to prohibit the use of human eggs to create embryos for research was put forward during the passage of the Act, but was soundly defeated in both Houses of Parliament.

\section{Anne McLaren}

Wellcome/Cancer Research Campaign Institute, Tennis Court Road, Cambridge CB2 1QR, UK

\section{Don't let politics put Diamond at risk}

Sir - It is with increasing dismay that I watch the antics over the siting of the new UK synchrotron, Diamond (see Nature 402, 451; 1999). The UK government now appears to be in dispute with the Wellcome Trust — the world's biggest medical charity. This has resulted in further delay to a facility which, in scientific terms, is overdue, as well as in harsh criticism of the Wellcome Trust by politicians and scientists.

Lest we forget, it is the Wellcome Trust, not the government, that has saved UK biomedical science: without its financial support, cuts to science funding would have been fatal. Do we seriously believe that the government (or voters) will put structural biology above tax cuts or hospital beds?

I think an open competition would have been the best way to decide on the siting of Diamond. But the Kafkaesque behaviour of the Office of Science and Technology has ensured that this is no longer an option. The choice is now between Daresbury in the north of England or Rutherford in the south.

My own preference would be for Daresbury. But if the cost of siting Diamond there is a loss of Wellcome involvement, then the price is too high. Wellcome is vital to the project, not only in cash terms (building a smaller synchrotron ring would be worse than useless), but also in contributing dynamic scientific and intellectual management expertise.

The United Kingdom has a chance to build a world-class facility in structural genomics to complement its world-class facilities in genome sequencing and bioinformatics. Both these rely on substantial support from the Wellcome Trust. We must have Diamond and we must have it soon - to lose or degrade such a precious jewel would be a disaster. James H. Naismith

Centre for Biomolecular Sciences, University of St Andrews, Fife KY16 9ST, UK 